\title{
Engineering solutions for food-energy-water systems: it is more than engineering
}

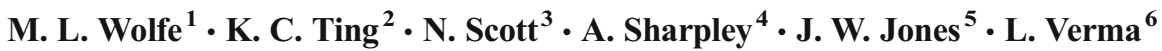

Published online: 27 January 2016

(C) The Author(s) 2016. This article is published with open access at Springerlink.com

\begin{abstract}
Food, energy, and water systems interact extensively, giving rise to the term "food-energy-water (FEW) nexus," with the term "nexus" signifying connectedness and interrelationships. A systems approach involving multidisciplinary and transdisciplinary teams and partnerships is needed to address complex challenges of the nexus. A concurrent cyber-
\end{abstract}

M. L. Wolfe

mlwolfe@vt.edu

K. C. Ting

kcting@illinois.edu

N. Scott

nrs5@cornell.edu

A. Sharpley

sharpley@uark.edu

J. W. Jones

jimj@ufl.edu

L. Verma

lverma@uark.edu

1 Virginia Tech, 155 Ag Quad Lane, Rm 200 Seitz Hall, Blacksburg, VA 24060, USA

2 University of Illinois at Urbana-Champaign, 338 Agricultural Engineering Sciences Building, MC-644, 1304 West Pennsylvania Ave., Urbana, IL 61801, USA

3 Cornell University, 332 Riley-Robb Hall, Ithaca, NY 14853, USA

4 University of Arkansas, 115 Plant Science Building, Fayetteville, AR 72701, USA

5 University of Florida, 289 Frazier Rogers Hall, P.O. Box 110570 , Gainesville, FL 32611, USA

6 University of Arkansas, 203 White Engineering Hall, Fayetteville, AR 72701, USA physical framework comprised of systems informatics, information analysis methods and tools, and systems analytics and decision support could provide a viable approach for addressing FEW system challenges. A fundamental requirement for implementing the framework is data. Needed data are often difficult to obtain; for example, while much agricultural production system data are collected, the data are not generally available. A priority for addressing FEW system challenges must be development of mechanisms for widespread curation and sharing of data; a few such efforts are underway. Implementing the framework also requires many collaborations. Creating new collaborations among multiple disciplines and organizations to implement the framework could be aided by convergence thinking, which engages approaches to problem solving that transcend disciplines and integrates knowledge from the physical, biological, social, and mathematical sciences and engineering to form comprehensive and integrated thinking at the interfaces of areas. A variety of organizations, private and public, can help in facilitating collaboration and partnerships among the disciplines. Government agencies, industry, academia, and professional societies can all play significant roles in furthering collaboration to address challenges in integrated FEW systems using a systems approach.

Keywords Convergence thinking $\cdot$ Cyber-physical framework · FEW nexus · Professional societies ·

Transdisciplinary

\section{Introduction}

Agricultural and biological engineers (ABEs) strive to ensure that the necessities of life are provided in a sustainable manner (ASABE 2015). They apply engineering principles to 
processes associated with managing natural resources and producing agriculturally based goods. Specifically, ABEs

- Develop solutions for responsible, sustainable uses of natural resources (soil, water, air, and energy) and agricultural products, by-products, and wastes.

- Devise practical, efficient solutions for producing, storing, transporting, processing, and packaging agricultural products.

- Solve problems related to systems, processes, and machines that interact with humans, plants, animals, microorganisms, and biological materials.

While ABEs bring strong systems thinking and problem solving abilities to bear, they recognize that complex challenges, such as those in food-energy-water (FEW) systems, require involvement of many different interests and fields of expertise. While interdisciplinary (integrated concepts and methods from different disciplines) work has taken place for many years, the increasing complexity of global challenges related to food, energy, and water requires a more concerted, broader effort to develop and implement a systems approach that involves all the needed actors. Two approaches that incorporate and reach beyond interdisciplinarity are transdisciplinarity and convergence thinking. Transdisciplinarity integrates the different types of knowledge that scientists and practitioners have such that both groups benefit from a mutual learning process (Scholz and Steiner 2015). For example, The Global Transdisciplinary Phosphorus Management project brought together scientists from various disciplines with practitioners (producers, phosphorus users, sewage plant operators, public agencies, NGOs, etc.) to work toward the common goal of sustainable P management (Scholz et al. 2015). Similar to transdisciplinarity, convergence thinking involves stakeholders beyond academic disciplines and engages persons from corporate, public, and private sectors, as well as academia, in bringing different technologies and sciences together for design and development of solutions.

Members of the American Society of Agricultural and Biological Engineers (ASABE) proposed a symposium at the 16th National Conference and Global Forum on Science, Policy, and the Environment: The Food-Energy-Water Nexus (http://foodenergywaternexus.org/) with the goal of initiating a conversation among ABEs, agricultural scientists, physical scientists, social scientists, and practitioners about working together to solve problems in integrated FEW systems. Specifically, we want to explore different approaches for developing and sustaining partnerships and collaborations focused on addressing challenges in the FEW nexus. While it is easy to say that partnerships and collaborations are needed, it can be difficult to initiate those partnerships and even more difficult to sustain them.
In this paper, we propose a concurrent cyber-physical framework approach to the FEW system. Data acquisition and accessibility are central to the proposed framework, and obtaining appropriate data across a variety of systems is a significant challenge in implementing such a framework. We illustrate this challenge with respect to agricultural production and natural resources systems and describe ongoing efforts to assemble research data. We believe that such an effort can be a model for data for other components of FEW systems. The proposed framework could be utilized for the overall FEW system or its specific components. As examples, we consider two specific systems of different scales: sustainable communities and the role of a particular element (phosphorus $(\mathrm{P})$ ) in FEW security. Lastly, we explore approaches for bringing together multiple interests and disciplines within the systems framework to address FEW challenges. We propose roles for professional societies, universities, government agencies, and industry.

\section{Systems approach for problem solving and decision making}

Systems analysis has long been used in problem solving and in providing analytical information to support decision making. One benefit of a systems approach is enabling the generation of value-added insights. A systems approach not only can be applied to provide decision support and solutions but can also be used to identify critical research questions. Successful applications often become foundations for further success in applying a systems approach; those successes provide valuable tools and information for addressing challenges in the implementation of a systems approach, such as (1) identifying systems leaders, i.e., task leaders who are familiar with the systems approach and systems experts who are able to lead; (2) abstracting systems, i.e., clearly defining and communicating the scope and objectives of the system under study; (3) handling uncertain and incomplete data and information; (4) delivering outcomes of analysis that are useful to the target audience; (5) enabling productive dynamics of contributors and participants, i.e., the ability to map the actions made at the component and subsystem level to the performance at the overall system level, as well as the distribution of responsibilities and sharing of credit; and (6) assembling and deploying human, information, fiscal, and physical resources. Past efforts have provided a wealth of information on systems theories and methodologies, and the technology readiness level is high for various systems approach tasks.

The following examples illustrate the successful use of a systems approach in a range of applications. Fang et al. (1990) applied a systems approach to develop a methodology and computational model for optimizing resource allocation in commercial greenhouse operations. The goal was to achieve 
annual economic returns, specifically for potted plant production systems, by considering the spatial and temporal factors. A second example focused on regenerative life support systems to satisfy the critical needs of air, water, and food supplies, as well as waste treatment and resource recovery, to support human space exploration over a long period of time. Such a life support system encompasses crew members, crop production, food preparation, waste processing, and resource recovery. A systems analysis and modeling effort were made to analyze each of the subsystems and their interactions to investigate the sustainability of life support systems (Fleisher et al. 2006; Ting et al. 2003).

The goal of a third project was to develop engineering solutions and machinery for successful production and provision of biomass feedstock using dedicated energy crops. The deliverables from the project include operating machinery design and prototypes, scientific information and engineering data, computational platforms, and decision support tools. Research was conducted on the following system tasks: (1) pre-harvest crop monitoring, (2) harvesting, (3) transportation, (4) storage, and (5) systems informatics and analysis. Models were used to investigate impact of size reduction and compression of biomass on supply chain costs and to study how long-term decisions interact with short-time decisions. Visualization tools and vehicle dispatch schemes were developed to display model results and optimize vehicle operating schedules (Shastri et al. 2011, 2014a, b; Lin et al. 2014).

\section{Food-energy-water systems}

Food, energy, and water systems are inextricably linked, giving rise to the term FEW nexus, with the term "nexus" signifying connectedness and interrelationships. Agricultural systems for food production are globally connected. Water and energy are necessary resources for food production. However, agriculture can have both beneficial and detrimental impacts on water quality and use efficiency, as well as on energy demand and supply. Global agricultural uses accounted for approximately $70 \%$ of the world's freshwater withdrawals in 2007 (Global Agriculture 2014). In 2010, agricultural use accounted for about $38 \%$ of total freshwater withdrawals in the USA (Maupin et al. 2014). Some parts of the world have excess rainfall that requires agricultural fields to be drained using engineered drainage systems, while other areas require engineered irrigation methods to support crop growth. In either case, the quality of water can be altered by the use of chemicals in agricultural production. As in many other industries, energy is needed to enable various agricultural tasks. On the other hand, agriculture can also be a producer of energy, such as the conversion of dedicated energy crops or agricultural residues and wastes into liquid fuel or thermal-electric power.
If we are to increase crop yields, create new crop varieties, develop new, cost-beneficial animal production systems, reduce greenhouse gas (GHG) emissions, and use less water and energy, we need to apply holistic thinking embodied in the convergence of science and technology. This way of thinking will look at issues of both large commercial operations and smallholder farmers as well as organic and conventional farming with a partnership including the numerous players from producers, academics, government, industry, and consumers.

Convergence thinking (NRC 2014), the application of insights and approaches from seemingly distinctly different disciplines, could be a key in developing fundamental ways to create new solutions for "big" problems in FEW systems. Convergence thinking engages approaches to problem solving that transcend disciplines and integrates knowledge from physical, biological, social, mathematical, and engineering sciences to form comprehensive and integrated thinking at the interfaces of areas. This thinking will focus on creation of new collaborations from academia, industry, government, foundations, national laboratories, and a diverse set of stakeholders from producers to consumers. A key concept of the convergence process is not only assembling the expertise but also the formation of a web of partnerships to transform research into practice.

To put these concepts into practice and address the challenges of the very complex FEW system, we must develop a systems approach that facilitates the following: (1) understanding of the interfaces among the components and of the whole system; (2) participation of a range of disciplinary experts, practitioners, and stakeholders in transdisciplinary processes to contribute and utilize information and knowledge; (3) provision of actionable decision support for a wide range of users, including scientists, engineers, policy makers, practitioners, etc.; and (4) inclusion of feedback, feedforward mechanisms for measurement, continuous improvement, and predictive power. In the following section, we propose a framework for such an approach.

\section{Proposed concurrent cyber-physical framework for FEW systems}

A modern FEW system needs to be an intelligenceempowered system that includes capability for information collection, information processing, and decision making; mechatronics devices for sensing, controls, and actions; and synergistic integration of components into functional systems. FEW system activities incorporate actions taken by many players in physical spaces. Ideally, these actions should be supported and guided by the intelligence obtained from analyses of information in cyber spaces. A cyber system consisting of effective content and efficient delivery methods will be very valuable in empowering farmers, manufacturers, 
consumers, and policy makers in their decision making (Ting 1997; Shastri et al. 2013).

Intelligence-enabling information technologies that can potentially empower FEW systems analysis, planning, design, management, and operation include (1) perception using sensing and data acquisition and management technologies (e.g., internet of things); (2) reasoning and learning involving mathematical, statistical, logical, and heuristic methodologies, handling of incomplete and uncertain information, and data mining (e.g., big data); (3) communication considering the contents, sources and recipients, and delivery platforms including wired, wireless, local area networks, wide area networks, the internet, and mobile technologies and devices (e.g., the nerves of information systems); (4) task planning and execution that involves control logic, planning of physical tasks, intelligent machines, robotics, and flexible automation work cells (i.e., physical capacity); and (5) systems integration to provide computational resources and capabilities of systems informatics, modeling, analysis, decision support, design and specifications, logistics and model-based control, concurrent science, engineering, and technology, and implementation (i.e., cyber-physical systems) (Chen et al. 2015).

Currently, systems integration is arguably the weakest aspect when addressing the nexus of FEW systems. An FEW systems concurrent analysis platform may be created based on the above-stated concept and framework using current and emerging informatics, analytics, and computational technologies (Ting and Partlow 2015). This cyber platform will facilitate the necessary systems integration tasks for sharing information among interested participants, conducting efficient analyses of local and global level issues, and creating valueadded information to support decisions and actions. Human users are the center of this networking platform. As alluded to above, three key dimensions in the platform are coupled to provide the users with desirable utilities:

Systems informatics - This contains the data, information, knowledge, and wisdom (i.e., intelligence) that are necessary for addressing the issues and/or deriving solutions. It also has an effective intelligence management method that enables identification of the source of intelligence, as well as the collection, sorting, storing, and retrieving of the information. Specifically, this part of the platform defines the FEW system's scope and objectives, identifies system constraints, establishes indicators of success, conducts system abstraction, and obtains and manages data.

Information analysis methods and tools-This provides analytical capability to process information mathematically, statistically, logically, heuristically, etc. The purpose is to seek new and/or integrated meanings of the information stored within the platform and/or entered by the users. It is expected to include various forms of computer simulation and optimization models and the ability to make the models work together to solve the problems that cannot be handled by individual models. The information processing tools should ideally come with the underlying assumptions, scopes of applicability, ways of handling incomplete and uncertain information, and their verification and validation.

Systems analytics and decision support-This is the part of the platform that returns the users the deliverables of the analyses. The first two parts enable the understanding and investigation of scenarios within FEW systems. Analytics are the outcomes of analyses presented in ways that measure and compare the status and performance of the system under consideration, as well as provide insights on what - ifs. The conclusions of analyses may be useful in supporting decision making, planning and executing actions, communicating analytical outcomes, and carrying out continuous monitoring and improvement.

Clearly, an FEW system's concurrent analysis platform will require many participants from a wide range of disciplines to make it function to its fullest extent. However, it is possible to start showing its usefulness when a critical amount of information, analytical tools, and actionable information become available and continue to evolve. The key is to systematically take necessary steps to involve key participants and configure a concurrent analysis platform structure that has the potential to be scaled up and scaled out.

We are not proposing that there will be one centrally managed entity that hosts and manages the entire system. Rather, we envision a community-wide design and development that will be distributed with connections designed for components as they are needed. The structure must be extensible, allow for innovative changes, and designed for evolution. Standards and protocols for a concurrent analysis platform structure need to be established; this could be done with the facilitation of professional organizations to work across disciplines. To some extent, this is as much a social behavior issue as a technical and scientific issue.

Although a number of examples could be cited that have some of the characteristics presented above, most decision support systems in agriculture have been rather narrow in scope, short-lived, and/or locally applicable. Here, we point out two worthy examples that are broad in their geographical coverage, include many actively contributing disciplinary scientists and partners, and are continually evolving in a distributed, participatory way. These examples could provide valuable insight for configuring a concurrent analysis platform structure that could be scaled up and scaled out.

One example is an information and decision support system in the southeast USA (including Florida, Alabama, Georgia, South Carolina, and North Carolina) that was started about 15 years ago. It integrates weather, crop, disease, water/ 
drought, and carbon and water footprint tools using databases that were brought together from different sources with models and algorithms for providing decision support to farmers and their advisors (Fraisse et al. 2013; www.AgroClimate.org). This system is now widely used in Florida by farmers, extension personnel, and water utilities. For example, it is widely used by strawberry growers in central Florida for managing fungicide applications for two major diseases in this crop. The growers have demonstrated that fungicide applications can be reduced by about $50 \%$ during drier years, which reduces costs of production and use of chemicals (www.usda.gov/oce/forum/2015_Speeches/ CFraisse.pdf). This integrated system was designed to be extensible and continues to serve as a platform for incorporating additional databases and decision tools. It is being adapted for use in South America and Africa in addition to other US states (e.g., www.wfo-oma.com/ climate-change/case-studies/decision-support-system-forrisk-reduction-in-agriculture-agroclimate-paraguay.html).

The Agricultural Model Intercomparison and Improvement Project (AgMIP; www.agmip.org), described briefly later, is a second example operating globally. Its strength is that it is a community of systems scientists and engineers involved in research in climate, economics, agronomy, soil physics, hydrology, livestock, plant diseases, sociology, computer science, and other disciplines. More than 30 projects are contributing to this effort. Emerging from this initiative are harmonized models and databases, protocols for intercomparing models, assessments of impacts and tradeoffs among systems, and a number of high-impact journal articles (e.g., Rosenzweig et al. 2013a, b; Nelson et al. 2013; Antle et al. 2015).

Neither of these examples would have been successful without very strong contributions and joint development by scientists and engineers from a number of different disciplines. Whereas both of these examples demonstrate convergence of disciplines, they do not necessarily demonstrate convergence of technologies themselves, although AgroClimate.org includes a convergence of information and communications technologies and a network of distributed sensors, using the web as well as smart phones to communicate DSS information to farmers (www.climate.gov/newsfeatures/decision-makers-toolbox/managing-agriculturalclimate-risks-us-southeast).

\section{Data: the foundation of systems modeling, analysis, and understanding}

There is a critical unmet need regarding data for developing, evaluating, improving, and applying agricultural models to study production systems at different scales. We currently do not have capabilities for accessing and using the very best quality data across time and space that agriculture is collecting. Researchers at land grant universities, the USDA, and other institutions perform thousands of experiments every year and collect accurate data on soil, weather, management, and crop and livestock performance. These data are used by researchers to compare new management systems, to evaluate ways of more efficient resource utilization (land, water, energy), and to limit environmental (air, soil, and water) contamination. However, these data are virtually lost after researchers use them, eliminating practical discovery, access, and use for evaluating and improving agricultural system models.

There needs to be a change in the culture regarding agricultural research data (Janssen et al. 2015). These data should serve as the foundation for evaluating and improving models and for providing evidence on the reliability of models for applications to major society issues, such as climate change and the challenges we face in feeding over nine billion people with limited land, water, and energy resources. There is an experiment station initiative now (with 13 land grant universities) to develop a National Agricultural Research Data Network for Harmonized Data (NARDN), with contributions from Kansas State University, Cornell University, University of Florida, other major universities, and the USDA Agricultural Research Service. The goal of this effort is to develop a prototype network over the next 5 years, with the main hub in the $\mathrm{Ag}$ Data Commons database at the National Agricultural Library (https://data.nal.usda.gov/) and with over 50,000 sets of research data. This project is also working with the CGIAR Consortium Office (www. cgiar.org/cgiar-consortium/), Bioversity International (www.bioversityinternational.org/), and the International Center for Tropical Agriculture (CIAT) (www.agtrials. org/) to enable connectivity globally.

In the USA, however, this system is only a start. All land grant universities need support to enable them to create local capabilities to help researchers working on agricultural systems research store their data in this network after publication. National funding to land grant experiment stations could help create a new culture for preserving valuable data and create a virtual laboratory where researchers can conduct a variety of modeling and analytics projects using data from different locations and years within the network. This effort could help the next generation of researchers gain invaluable experience by working with the data in the NARDN that would not be possible working only with site-specific datasets. Agricultural researchers and administrators at all levels need to recognize this critical need and collectively support a coordinated effort at national, state, and local levels. 


\section{FEW systems examples}

FEW systems can be defined at a wide range of scales, with an accompanying range of components. In this section, we explore the components of two very different types of systems with respect to the proposed FEW systems concurrent analysis platform. First, we consider sustainable communities, for which well-functioning FEW systems are essential, along with other related characteristics. Second, we consider the role of phosphorus in FEW system stability and security.

\section{Sustainable communities}

In the context of today's depressed economies, aging infrastructure, shifting demographics, environmental stresses, changing climate, and uncertain energy prices and availability, the need to plan for the long-term resiliency of communities is increasingly vital to ensure future growth and success. Community health and well-being depend not only on meeting economic, social, and environmental objectives but, more importantly, on integrating them. Future community development approaches that are rooted at the neighborhood level and driven by sustainability can at once address local development needs while ensuring fair opportunities for both current and future residents.

A transdisciplinary approach will be required to successfully address the triple bottom line of economic, social, and environmental development objectives and achieve long-term results. A diverse group of stakeholders from community, public, academic, and private partners must be brought together to engage with one another and discuss the needs of the local community. Throughout this effort, sustainable options and opportunities should be evaluated with attention to maintaining balance between potential economic, social, and environmental outcomes. The following definition of sustainable development may provide guidance in these efforts:

\section{Sustainable development is a process of change in which the direction of investment, the orientation of technology, the allocation of resources, the development and functioning of institutions, and the advancement of human and community well-being meet present needs and aspirations without compromising the ability of fu- ture generations to meet their own needs and aspirations (adapted from Brundtland 1987).}

Thus, sustainable development is a "process" of redirection, reorientation, and reallocation, i.e., an evolving concept rather than a fixed definition. It is a fundamental design or redesign of technological, economic, and sociological processes to address change. A vision of sustainable community revitalization begins with identifying key elements for a sustainable community. For example, Cloutier et al. (2014) included nine subsystems in the Sustainable Neighborhoods for Happiness Index that they developed to assess the relative status of communities with respect to development and happiness. Stakeholders could consider those nine components and identify the characteristics of each component that would describe a sustainable community (Table 1).

The most effective efforts will integrate these components (Table 1) through a systems-based approach, beginning at the neighborhood level and using place-based strategies contextually growing from, and enhancing, each community's identity and capacity. They will emerge from a full understanding of existing development needs and be scalable in their approach, making use of the extant and potential assets and resources of cities and regions. It is important to emphasize that this approach is scalable from a small rural community to neighborhoods within small cities or large cities.

\section{The role of phosphorus in FEW system stability and security}

Phosphorus (P) is an essential element for crop and livestock production. Over the past 50 years, global fertilizer $P$ use has increased $350 \%$, and food production has more than doubled (Khan et al. 2009). Along with this, however, global flows of $P$ have increased fourfold (Childers et al. 2011; Haygarth et al. 2014), with distinct areas of grain and animal production functioning in geographically disparate, yet cost-efficient systems. The main consequence of this uncoupling of production systems has been a one-way transfer of P (as feed, fertilizer, and manure) to localized grain and livestock production and human consumption and a reduction in the efficiency of $\mathrm{P}$ reuse. In fact, $80 \%$ of the $\mathrm{P}$ mined from phosphate rock does not make it to food consumed by the global population (Neset and Cordell 2012), with only $10 \%$ in human wastage recycled back to agricultural lands (Elser and Bennett 2011). This production system intensification and decoupling have exacerbated the risk of $\mathrm{P}$ loss to water and associated eutrophication (Kleinman et al. 2015; Sharpley and Jarvie 2012).

These inefficiencies of $\mathrm{P}$ utilization are of increasing concern for three reasons. First, unlike nitrogen $(\mathrm{N})$, which is a renewable atmospheric resource, phosphate rock is a finite, non-renewable resource, with economically extractable supplies that are geographically limited (Jasinski 2015), that cannot be manufactured or substituted by any other element. Second, the increasing incidence and severity of surface water eutrophication and associated harmful algal toxic blooms worldwide have recently started to impact general urban populations (Carpenter 2008; Schindler et al. 2008). Third, mandates to expand biofuel production in every continent to increase future national energy security and reduce reliance on fossil fuels have added pressure on $\mathrm{P}$ fertilization of biofuel feedstocks (Hein and Leemans 2012). Biofuel feedstocks, 
Table 1 Some characteristics of an "ideal" sustainable community

\begin{tabular}{|c|c|}
\hline Component & Characteristics of component \\
\hline \multirow[t]{2}{*}{ Food } & -Significant local food production \\
\hline & •Ensure adequate nutrition \\
\hline \multirow[t]{5}{*}{ Energy } & -Renewable energy systems to meet all energy needs \\
\hline & -High level of energy conservation \\
\hline & •Local "smart" grid \\
\hline & -Minimal carbon footprint \\
\hline & •Minimal gaseous emissions (GHG) \\
\hline \multirow[t]{2}{*}{ Water } & -Water conservation measures \\
\hline & -Efficient and recycled water use \\
\hline \multirow[t]{2}{*}{ Waste } & -Materials recycling \\
\hline & -Efficient and recycled waste management (including human) \\
\hline Transportation & -A basic infrastructure \\
\hline Buildings & •"Healthy” green buildings \\
\hline \multirow[t]{5}{*}{ Urban design } & -Urban design that is efficient and convenient \\
\hline & $\begin{array}{l}\text {-Close-proximity relationship for "live, work, and play" to } \\
\text { minimize transportation }\end{array}$ \\
\hline & •"Green" spaces, including biking and walking trails \\
\hline & $\begin{array}{l}\text {-Diverse living environment (intergenerational, affordable } \\
\text { housing, senior housing, assisted living) }\end{array}$ \\
\hline & $\begin{array}{l}\text {-Attractive recreational and educational opportunities (community } \\
\text { centers) }\end{array}$ \\
\hline Business and economic development & $\begin{array}{l}\text {-Active and thriving businesses with excellent local job } \\
\text { opportunities }\end{array}$ \\
\hline \multirow[t]{2}{*}{ Governance and communication } & -Effective communication systems (including internet of things) \\
\hline & -Community governance \\
\hline
\end{tabular}

such as sugarcane, wheat, corn, and sugar beet for bioethanol production and rapeseed, soybean, and palm oil for biodiesel production, now compete for land, water, and P use for food production. These pressures can increase the risk of $\mathrm{P}$ loss to surface waters (i.e., affecting water security) and grain prices with competition for food or fuel (i.e., affecting food security) (Robertson et al. 2008; Tilman et al. 2009). Clearly, P is a key element to the stability and security of the FEW nexus (Jarvie et al. 2015).

Efforts to stabilize the role of $\mathrm{P}$ in the FEW nexus will involve more than engineering. Solutions will involve embracing the "5 R's" of P use and management: restructuring of production systems, realignment of system inputs of $\mathrm{P}$ to increase utilization of $\mathrm{P}$ sources, recovery of $\mathrm{P}$ from waste, reuse of $\mathrm{P}$ from manures and residuals, and reducing $\mathrm{P}$ loss through targeted precision conservation (based on Schoumans et al. 2015; Sharpley et al. 2015b). This is a holistic update of the "4R" nutrient management stewardship (right form, right time, right place, and right amount) espoused by the International Fertilizer Association (IFA 2009) and International Plant Nutrition Institute (IPNI 2014).

Experience tells us that there needs to be a general restructuring and realignment of production systems to more closely connect crop and livestock operations, which includes a maximum threshold level of $\mathrm{P}$ use and a minimum level of land conservation that avoids risky practices on vulnerable landscapes. In extreme cases of highly vulnerable landscapes, certain production systems may be inherently unsustainable, regardless of the suite of conservation practices used or conservation measures adopted. Precision conservation and nutrient management programs can address $P$ source realignment (e.g., rate, method, and timing of applied $\mathrm{P}$ ) and reduce $\mathrm{P}$ loss through transport controls (e.g., conservation tillage, contour ploughing, cover crops, and riparian buffers) to achieve the required improvements in water quality and security.

A greater recovery and reuse of $\mathrm{P}$ at global, regional, local, and even farm scales can alleviate phosphate rock supply and security concerns to a certain degree. The fertilizer value of $P$ in manures and urban and other byproducts should be properly accounted for with standardized analytical methods in watershed management and strategy implementation planning. This could include development of innovative cost-effective technologies and practices for manure processing and production of higher value recycled products. However, their initial use in agricultural production systems will likely be encouraged with financial incentives, along with stricter use requirements or regulations. 
In reducing $\mathrm{P}$ loss, lessons from the indirect consequences or trade-offs of conflicting strategies must be learned and management strategies adapted. For example, no-till conservation has dramatically decreased erosion and associated $\mathrm{P}$ loss, although the loss of $\mathrm{P}$ in dissolved, more immediately reactive form without the incorporation of applied $\mathrm{P}$ can reverse total $\mathrm{P}$ gains and be sufficient to stimulate algal blooms (Richards et al. 2010; Sharpley and Smith 1994; Tiessen et al. 2010). Another trade-off resulting from the cultivation of new lands fueled by corn for bioethanol that is facilitated by tile drainage will directly connect new source areas to stream and ditches, indirectly increasing the potential for P loss (Smith et al. 2014, 2015). Clearly, there needs to be a more effective communication and coordination among all involved in agricultural production, policy development, and strategy implementation.

Finally, ongoing development of nutrient criteria for waters of the USA should address what is achievable and affordable, given that pristine "reference" conditions may not be achievable in some watersheds with intensive agricultural production (Scott and Haggard 2015; White et al. 2014). Concurrent with this, cost-benefit analyses of nutrient reduction strategies are necessary to determine what is achievable, affordable, and even desired by the majority of watershed stakeholders.

\section{Facilitating and promoting partnerships and collaboration}

Scott et al. (2016) suggest how convergence can be adopted and applied within agriculture, food, and natural resources systems (AFNS), including FEW systems. They contend that we need to create teams that address the complex problems of AFNS with approaches of convergence through, for example, emerging platforms of nanotechnology, biotechnology, information science, and cognitive science.

We need to create teams of individuals that pursue research, education, and outreach with a lens of convergence thinking. This effort can also catalyze stakeholders to identify the emerging and most critical topics. In contrast to the Coordinated Agricultural Projects (CAPs) of the recent past funded by the USDA-NIFA Agriculture and Food Research Initiative (AFRI; http://nifa.usda.gov/afri-regional-bioenergysystem-coordinated-agricultural-projects) that promoted large multiinstitutional projects, individual campuses need to mobilize the talent across the campus to engage scientists and engineers who commit to work as a team to study the problem as a convergence of technologies. Physicists, chemists, plant scientists, animal scientists, engineers, food scientists, computer scientists, biologists, social scientists, and economists are examples but are not meant to limit the expertise of team participants. The team will reach out to include a broad spectrum of persons from industry, governments, producers, and consumers.

While there are good examples in which teams of researchers from different disciplines have collaborated closely in empirical studies in the field, fewer examples exist in which those disciplines have worked together to develop and evaluate system models that are critical to the study of the FEW nexus. For example, engineers have cooperated with agronomists, plant physiologists, soil scientists, and economists in research on cropping system models. These collaborations have been important; however, there is at least one discipline that has not typically been cooperating with agricultural system modelers, yet it has a major role in the design of cropping systems. Plant breeders and geneticists have largely been doing their work on plant selection, genomics, and genetic engineering with little, if any, input to agricultural models. One notable exception is the Global Futures project of the CGIAR, led by the International Food Policy Research Institute (IFPRI). In that project, plant breeders have worked with agronomists, crop modelers, and economists to quantify target breeding traits for simulating "virtual genotypes" and evaluating their impacts on food production, trade, and food security globally (Rosegrant et al. 2014). Furthermore, a research team of crop modelers, geneticists, plant breeders, and agronomists at the University of Florida has worked with CIAT to show that it is now possible to incorporate genetic information into crop models to increase their reliability and ability to mimic variations across genetics and environments (e.g., Chenu et al. 2009; Boote et al. 2016; Messina et al. 2006, 2011). This progress clearly demonstrates the need to broaden the typical disciplines working on crop and livestock models to include breeders and geneticists to create a next generation of food production models.

The AgMIP was developed to foster these types of interactions in order to greatly increase our capabilities to understand agricultural systems and to predict their performance (Rosenzweig et al. 2013a, 2014; Asseng et al. 2013). Although the main emphasis of AgMIP has been to evaluate and improve models for climate change impact and adaptation studies, it has evolved to be a more holistic community of agricultural systems modelers and now serves as a platform for many initiatives with connections to many universities globally.

Universities can play a significant role in bringing teams together both within their individual campuses and across universities and organizations, e.g., by providing facilitators, incentives, and financial support to teams. Universities also have a key role in providing curricula to produce graduates with skill competencies to address complex challenges in FEW systems. These skills need to include disciplinary skills as well as collaborative skills, which will facilitate transdisciplinarity and convergence thinking. Currently, there tends to be an emphasis on competition rather than on 
collaboration in advanced education, so there is a tendency for organizations to focus more on their own solutions rather than partnership solutions, even if their solutions might only be piecemeal. This behavior needs to be discouraged, whereas there needs to be more effort in encouraging broad thinking and collaborative partnerships. Such professionals are needed to fill a critical global void and will continue to be in great demand.

Funding agencies should consider allocating some funding to supporting teams that demonstrate a commitment to operating in the space of convergence in FEW systems. Agencies could develop areas where they wish to seek proposals from groups or encourage proposals from groups who will define proposed areas of research, education, and outreach. In every case, the team will be required to include matching funds to match with agency funds. This requirement is likely to ensure participation of industry and others from the beginning.

\section{Role of professional societies}

ASABE has a long history of providing resources to help its member engineers solve problems in food, agriculture, natural resources, and the environment. Recognizing the need to connect its members and partner societies to address emerging challenges as a global community, ASABE implemented an initiative, "Global Partnerships for Global Solutions: An Agricultural and Biological Engineering Global Initiative," in 2012 toward achieving its global vision:

\section{"ASABE will be among the global leaders that provide engineering and technological solutions toward creat- ing a sustainable world with abundant food, water, and energy, and a healthy environment."}

ASABE has published a white paper (ASABE 2015) that outlines the grand challenges that the world is facing, highlights the specific needs of the three "security" themes (food security, energy security, and water security) in the context of sustainability and climate change, and discusses how ASABE, its members, and its partners will address these grand challenges as the year 2050 approaches. ASABE (2015) identified the following goals for ABEs: (1) improve food productivity; (2) reduce food losses and waste; (3) enhance energy conservation and efficiency; (4) develop adaptable renewable energy systems; (5) improve water availability, conservation, and efficient use; and (6) provide clean water for multiple uses (human consumption, agriculture, recreation, ecosystem services, biodiversity, etc.).

Other professional societies have also identified the need for and interest in partnerships. For example, the theme of the 2015 Annual Meetings of the American Society of Agronomy (ASA), Crop Science Society of America (CSSA), and Soil
Science Society of America (SSSA) (the Tri-Societies) was "Synergy in Science: Partnering for Solutions," and for 2016, the theme will be "Resilience Emerging from Scarcity and Abundance." In 2015, ASA/CSSA/SSSA issued a call for white papers (www.crops.org/science-policy/get-involved/ infews-white-papers) to help inform the National Science Foundation (NSF) in identifying research priorities for its Innovations at the Nexus of Food, Energy, and Water Systems (INFEWS) funding program. The resulting FEW White Paper Database (www.crops.org/science-policy/whitepapers) includes a variety of papers, including one focused on phosphorus stewardship for resilience in FEW security (Sharpley et al. 2015a). Clearly, issues central to FEW nexus security are a priority for the Tri-Societies now and into the future.

Professional societies could provide appropriate expertise to facilitate development of partnerships and collaborations focused on addressing FEW systems challenges. Some examples of activities that professional societies could collaboratively or individually address include the following:

- Societies could host conferences or workshops designed to bring together individuals from multiple disciplines with the intention of developing partnerships or collaborations to focus on specific topics or goals.

- Cross-society committees or task groups could be formed to focus on specific aspects of FEW systems, to submit proposals for funding, prepare issue papers, or meet other goals.

- Leadership of multiple societies could meet with the specific objective of developing specific goals and action plans for partnerships focused on various aspects of FEW systems. Individuals who are active members across two or more societies would be valuable resources, e.g., co-author J. W. Jones is a Fellow of ASA, ASABE, and SSSA.

- Societies could help lead the development of standards and protocols for interconnecting distributed components of proposed cyber-physical platforms and frameworks.

- Societies could collaborate in providing information to federal agencies and legislators on the importance of funding collaborative research (convergence approach). For example, the Charles Valentine Riley Memorial Foundation (http://rileymemorial.org/) and its partners are including the perspective of scientific societies in developing a unified message in support of publicly funded food, agricultural, and natural resources research. Here, 27 US scientific societies were invited to participate in a facilitated conversation in December 2015 to share their perspectives and insights.

- Societies could facilitate interaction of industry, government, and academia among members within a society as well as across societies. 


\section{Summary}

Food-energy-water systems are complex. Engineering and technology developed and implemented via a systems approach are critical to addressing FEW systems challenges. A concurrent cyber-physical framework comprised of systems informatics, information analysis methods and tools, and systems analytics and decision support could provide a viable approach for addressing FEW systems challenges. Many different disciplines are required to populate and implement the framework. A variety of organizations, private and public, can help facilitate collaboration and partnerships among disciplines. Government agencies, industry, academia, and professional societies can all play significant roles in furthering collaboration to address FEW systems challenges.

Open Access This article is distributed under the terms of the Creative Commons Attribution 4.0 International License (http:// creativecommons.org/licenses/by/4.0/), which permits unrestricted use, distribution, and reproduction in any medium, provided you give appropriate credit to the original author(s) and the source, provide a link to the Creative Commons license, and indicate if changes were made.

\section{References}

Antle JM, Basso BO, Conant RT, Godfray C, Jones JW, Herrero M, Howitt RE, Keating BA, Munoz-Carpena R, Rosenzweig C, Tittonell P, Wheeler TR (2015) Towards a new generation of agricultural system models, data, and knowledge products: model design, improvement, and implementation. AgMIP. www.agmip.org/ refbase/uploads/antle/2015/220_Antle2015.pdf. Accessed 7 January 2016

ASABE (2015) Global partnerships for global solutions: an agricultural and biological engineering global Initiative. ASABE, St. Joseph, Michigan. www.asabe.org/media/195967/globalinitiative.pdf. Accessed 7 January 2016

Asseng S, Ewert F, Rosenzweig C, Jones JW, Hatfield JL, Ruane AC, Boote KJ, Thorburn PJ, Rötter RP, Cammarano D (2013) Uncertainty in simulating wheat yields under climate change. Nat Climate Change 3(9):827-832

Boote KJ, Vallejos CE, Jones JW, Correll MJ (2016) Crop modeling approaches for predicting phenotype of grain legumes with linkage to genetic information. In: Yin X, Struik PC (eds) Crop systems biology. Springer International Publishing, Switzerland, pp 163-192

Brundtland GF (1987) World commission on environment and development. Oxford University Press, Oxford

Carpenter SR (2008) Phosphorus control is critical to mitigating eutrophication. Proc Natl Acad Sci U S A 106(32):11030-11040

Chen N, Zhang X, Wang C (2015) Integrated open geospatial web service enabled cyber-physical information infrastructure for precision agriculture monitoring. Comput Electron Agr 111:78-91

Chenu K, Chapman SC, Tardieu F, McLean G, Welcker C, Hammer GL (2009) Simulating the yield impacts of organ-level quantitative trait loci associated with drought response in maize: a "gene-tophenotype" modeling approach. Genetics 183(4):1507-1523

Childers DL, Corman J, Edwards M, Elser JJ (2011) Sustainability challenges of phosphorus and food: solutions from closing the human phosphorus cycle. Bioscience 61:117-124
Cloutier SA, Jambeck JR, Scott NR (2014) The sustainable neighborhoods for happiness index: a metric for assessing a community's potential influence on residential happiness. Ecol Indic 40:147-152

Elser JJ, Bennett E (2011) A broken biogeochemical cycle. Nature 478: 29-31

Fang W, Ting KC, Giacomelli GA (1990) Optimizing resource allocation for greenhouse potted plant production. T ASAE 33(4):1377-1382

Fleisher DH, Rodriguez L, Both AJ, Cavazzoni J, Ting KC (2006) Advanced life support systems in space. In: Chapter 5 Precision Agriculture. CIGR Handbook of Agricultural Engineering Volume VI Information Technology. ASABE, St. Joseph, Michigan, pp 339-354

Fraisse CW, Andreis JH, Pavan W (2013) AgroClimate decision support system: from web-based solutions to mobile apps. In: Proceedings EFITA WCCA CIGR 2013 - Sustainable Agriculture through ICT Innovation, Turino, Italy, 24-27 June 2013. http://www.cigr.org/ Proceedings/uploads/2013/0190.pdf. Accessed 7 January 2016

Global Agriculture (2014) Water withdrawal by sector, around 2007. www.globalagriculture.org/fileadmin/files/weltagrarbericht/ AquastatWithdrawal2014.pdf. Accessed 7 January 2016

Haygarth PM, Jarvie HP, Powers SM, Sharpley AN, Elser JJ, Shen J, Peterson HM, Chan N-I, Howden NJK, Burt T, Worrall F, Zhang F, Liu X (2014) Sustainable phosphorus management and the need for a long-term perspective: the legacy hypothesis. Environ Sci Technol 48:8417-8419

Hein L, Leemans R (2012) The impact of first-generation biofuels on the depletion of the global phosphorus reserve. Ambio 41:341-349

IFA (2009) The global "4R" nutrient stewardship framework: developing fertilizer best management practices for delivering economic, social and environmental benefits. International Fertilizer Industry Association, Paris. www.ipni.net/ipniweb/portal/4r.nsf/0/ BAB4157B488871A385257DF100739D94/\$FILE/The\% 20Global\%204R\%20Nutrient\%20Stewardship\%20Framework.pdf. Accessed 7 January 2016

IPNI (2014) 4R nutrient stewardship portal. International Plant Nutrition Institute, Peachtree Corners. www.ipni.net/4R. Accessed 7 January 2016

Janssen S, Porter CH, Moore AD, Athanasiadis IN, Foster I, Jones JW, Antle JM (2015) Towards a new generation of agricultural system models, data, and knowledge products: building an open web-based approach to agricultural data, system modeling and decision support. AgMIP. www.agmip.org/refbase/uploads/janssen/2015/221 Janssen2015.pdf. Accessed 7 January 2016

Jarvie HP, Sharpley AN, Flaten D, Kleinman PJA, Jenkins A, Simmons T (2015) The pivotal role of phosphorus in a resilient water-energyfood security nexus. J Environ Qual 44(5):1308-1326

Jasinski S (2015) Phosphate rock In: Mineral commodity summaries. U.S. Department of the Interior and U.S. Geological Survey. http:// minerals.usgs.gov/minerals/pubs/mcs/2014/mcs2014.pdf. Accessed 7 January 2016

Khan S, Khan MA, Hanjra MA, Mu J (2009) Pathways to reduce the environmental footprints of water and energy inputs in food production. Food Policy 34:141-149

Kleinman PJA, Sharpley AN, Withers PJA, Bergstrom L, Johnson LT, Doody DG (2015) Implementing agricultural phosphorus science and management to combat eutrophication. Ambio 44(Supp. 2): 297-310

Lin T, Rodriguez LF, Shastri YN, Hansen AC, Ting KC (2014) Integrated strategic and tactical biomass-biofuel supply chain optimization. Bioresource Technol 156:256-266

Maupin MA, Kenny JF, Hutson SS, Lovelace JK, Barber NL, Linsey KS (2014) Estimated use of water in the United States in 2010. U.S. Geological Survey Circular 1405. http://dx.doi.org/10.3133/ cir1405. Accessed 7 January 2016 
Messina CD, Jones JW, Boote KJ, Vallejos CE (2006) A gene-based model to simulate soybean development and yield responses to environment. Crop Sci 46:456-466

Messina CD, Podlich D, Dong Z, Samples M, Cooper M (2011) Yieldtrait performance landscapes: from theory to application in breeding maize for drought tolerance. J Exp Bot 62(3):855-868

Nelson GC, Valin H, Sands RD, Havlik P, Ahammad H, Deryng D, Elliott J, Fujimori S, Hasegawa T, Heyhoe E, Kyle P, Von Lampe M, LotzeCampen H, d'Croz DM, van Meijl H, van der Mensbrugghe D, Muller C, Popp A, Roberston R, Robinson S, Schmid E, Schmitz C, Tabeu A, Willenbockel D (2013) Climate change effects on agriculture: economic responses to biophysical shocks. Proc Natl Acad Sci U S A 111(9):3274-3279. doi:10.1073/pnas.1222465110

Neset T-SS, Cordell D (2012) Global phosphorus scarcity: identifying synergies for a sustainable future. J Sci Food Agr 92:2-6

NRC (2014) Convergence: facilitating transdisciplinary integration of life sciences, physical sciences, engineering, and beyond. National Research Council, The National Academies Press, Washington, D.C

Richards RP, Baker DB, Crumrine JP, Sterns AM (2010) Unusually large loads in 2007 from the Maumee and Sandusky Rivers, tributaries to Lake Erie. J Soil Water Conserv 65:450-462

Robertson GP, Dale VH, Doering OC, Hamburg SP, Melillo JM, Wander MM, Parton WJ, Adler PR, Barney JN, Cruse RM, Duke CS, Fearnside PM, Follett RF, Gibbs HK, Goldemberg J, Mladenoff DJ, Ojima D, Palmer MW, Sharpley A, Wallace L, Weathers KC, Wiens JA, Wilhelm WW (2008) Agriculture - sustainable biofuels redux. Science 322:49-50

Rosegrant MW, Koo J, Cenacchi N, Ringler C, Robertson R, Fisher M, Cox C, Garrett C, Nicostrato D, Perez D, Sabbagh P (2014) Food security in a world of natural resource scarcity. IFPRI. doi:10.2499/ 9780896298477. Accessed 7 January 2016

Rosenzweig C, Jones JW, Hatfield JL, Ruane AC, Boote KJ, Thorburn P, Antle JM, Nelson GC, Porter C, Janssen S (2013a) The agricultural model intercomparison and improvement project (AgMIP): protocols and pilot studies. Agr Forest Meteorol 170:166-182

Rosenzweig C, Elliott J, Deryng D, Ruane AC, Arneth A, Boote KJ, Folberth C, Glotter M, Müller C, Neumann K, Piontek F, Pugh T, Schmid E, Stehfest E, Jones JW (2013b) Assessing agricultural risks of climate change in the 21st century in a global gridded crop model intercomparison. Proc Natl Acad Sci U S A. doi:10.1073/pnas. 1222463110

Rosenzweig CJ, Elliott D, Deryng AC, Ruane A, Arneth KJ, Boote C, Folberth M, Glotter N, Khabarov C, Müller K, Neumann F, Piontek T, Pugh E, Schmid E, Stehfest JJW (2014) Assessing agricultural risks of climate change in the 21st century in a global gridded crop model intercomparison. Proc Natl Acad Sci U S A 111(9):32683273. doi: $10.1073 /$ pnas. 1222463110

Schindler DW, Hecky RE, Findlay DL, Stainton MP, Parker BR, Paterson MJ, Beaty KG, Lyng M, Kasian SEM (2008) Eutrophication of lakes cannot be controlled by reducing nitrogen input: results of a 37-year whole-ecosystem experiment. Proc Natl Acad Sci U S A 106:11254-11258

Scholz RW, Steiner G (2015) Transdisciplinarity at the crossroads. Sustain Sci 10:521-526. doi:10.1007/s11625-015-0338-0

Scholz RW, Hellums DT, Roy AA (2015) Global sustainable phosphorus management: a transdisciplinary venture. Cur Sci India 108(7): $1237-1246$

Schoumans OF, Bouraoui F, Kabbe C, Oenema O, van Dijk KC (2015) Phosphorus management in Europe in a changing world. Ambio 44(Supp. 2):S180-S192

Scott JT, Haggard BE (2015) Implementing effects-based water quality criteria for eutrophication in Beaver Lake, Arkansas: linking standard development and assessment methodology. J Environ Qual 44(5):1503-1512

Scott NR, Chen H, Schoen R (2016) Sustainable global food supply. In: Bainbridge WB, Roco MC (eds) Handbook of science and technology convergence. Springer International, Switzerland

Sharpley AN, Jarvie HP (2012) Agricultural management, water quality and ecology: putting practice into policy. In: Eaglesham A (ed) National Agricultural Biotechnology Council Conference Proceedings No. 24. Boyce Thompson Institute, Ithaca, N.Y. Library of Congress \#2012954078, p 87-116

Sharpley AN, Smith SJ (1994) Wheat tillage and water quality in the Southern Plains. Soil Till Res 30:33-48

Sharpley AN, Jarvie HP, Kleinman PJA, Flaten D (2015a) Reframing phosphorus stewardship for resilience in food-energy-water security. White Paper Database, Crop Science Society of America. www.crops.org/science-policy/white-papers/view/2. Accessed 7 January 2016

Sharpley AN, Bergström L, Aronsson H, Bechmann M, Bolster C, Börling K, Djodjic F, Jarvie H, Schoumans O, Stamm C, Tonderski K, Ulen B, Uusitalo R, Withers P (2015b) Future agriculture with minimized phosphorus losses to waters: research needs and direction. Ambio 44(Supp. 2):S163-S179

Shastri Y, Rodriguez L, Hansen A, Ting KC (2011) Development and application of BioFeed model for optimization of herbaceous biomass feedstock production. Biomass Bioenerg 35(7):2961-2974

Shastri YN, Hansen AC, Rodriguez LF, Ting KC (2013) Systems informatics and analysis of biomass feedstock production. Pertanika J Sci Technol 21(1):273-280

Shastri YN, Miao Z, Rodriguez LF, Grift TE, Hansen AC, Ting KC (2014a) Determining optimal size reduction and densification for biomass feedstock using the BioFeed optimization model. Biofuel Bioprod Bior 8:423-437

Shastri Y, Hansen AC, Rodriguez LF, Ting KC (2014b) Systems informatics and analysis. In: Engineering and science of biomass production and provision, Springer, p 195-232

Smith DR, King KW, Johnson L, Francesconi W, Richards P, Baker D, Sharpley AN (2014) Surface runoff and tile drainage transport of phosphorus in the midwestern United States. J Environ Qual 44(2): 495-502

Smith DR, King KW, Williams MR (2015) What is causing the harmful algal blooms in Lake Erie? J Soil Water Conserv 70(2):27A-29A

Tiessen KHD, Elliot JA, Yarotski J, Lobb DA, Flaton DN, Glozier NE (2010) Conventional and conservation tillage: Influence on seasonal runoff, sediment, and nutrient losses in the Canadian Prairies. J Environ Qual 39:964-980

Tilman D, Socolow R, Foley JA, Hill J, Larson E, Lynd L, Pacala S, Reilly J, Searchinger R, Somerville C, Williams R (2009) Beneficial biofuels - the food, energy, and environment trilemma. Science 325:270-271

Ting KC (1997) Automation and systems analysis. In: Plant production in closed ecosystems, Kluwer Academic Publishers, p 171-187

Ting KC, Partlow KC (2015) Establishing a world hunger abatement task (WHAT) to build intelligent food systems (IFS)-managing the WHAT-IFS. Resource, March/April 2015:6

Ting KC, Fleisher DH, Rodriguez LF (2003) Concurrent science and engineering for phytomation systems. J Agric Meteorol 59(2):93-101

White MA, Haggard BE, Scott JT (2014) A review of stream nutrient criteria development in the United States. J Environ Qual 42: $1002-1014$ 